\title{
Cardiac Rehabilitation: Under-utilized globally
}

Sherry L. Grace, $\mathrm{PhD}^{1,2}$, Kornelia Kotseva, $\mathrm{MD}, \mathrm{PhD}^{3} \&$ Mary A. Whooley, $\mathrm{MD}^{4}$

${ }^{1}$ Faculty of Health, York University, Toronto, Canada.

${ }^{2}$ KITE-Toronto Rehabilitation Institute \& Peter Munk Cardiac Centre, University Health

Network, University of Toronto, Toronto, ON, Canada

${ }^{3}$ National Institute for Prevention and Cardiovascular Health, National University of Ireland, Galway, Ireland, \& Imperial College Healthcare NHS Trust, London, UK;

kornelia.kotseva@nuigalway.ie

${ }^{4}$ US Department of Veterans Affairs Quality Enhancement Research Initiative, \& University of California, San Francisco, USA; Mary.Whooley@va.gov

Correspondence to: Prof. Sherry L. Grace, PhD, CRFC, FCCS, FAACVPR, Bethune 368, Faculty of Health, York University, 4700 Keele Street, Toronto, ON, Canada, M3J 1P3. Email: sgrace@yorku.ca; twitter @ sherrylgrace; Phone: (416) 736-2100 x.20575 


\begin{abstract}
Purpose of review:

Cardiac rehabilitation (CR) is grossly under-utilized. This review summarizes current knowledge about degree of CR utilization, reasons for under-utilization, and strategies to increase use.
\end{abstract}

$\underline{\text { Recent findings: }}$

ICCPR's global CR audit quantified for the first time the number of additional CR spots needed per year to treat indicated patients, so there are programs they may use. The first randomized trial of automatic/systematic CR referral has shown it results in significantly greater patient completion. Moreover, the recent update of the Cochrane review on interventions to increase use has provided unequivocal evidence on the significant impact of clinician CR encouragement at the bedside; a course is now available to train clinicians.

Summary:

The United States is leading the way in implementing automatic referral with inpatient-clinician CR discussions. Suggestions to triage patients based on risk to less resource-intensive, unsupervised program models could simultaneously expand capacity and support patient adherence.

Keywords: cardiac rehabilitation, referral, access to health care, health care utilization, secondary disease prevention, cardiovascular diseases 


\section{Introduction}

Cardiovascular diseases (CVD) are among the leading causes of mortality and morbidity globally, with rising incidence in low and middle-income countries (LMICs)(1). With advances in screening and associated risk factor control as well as acute treatments, most cardiac patients survive upon initial diagnosis, but then live with CVD chronically at an increased risk of mortality and further morbidity(2).

Cardiac rehabilitation (CR) is a standardized outpatient model of care for secondary prevention, delivering risk factor control strategies, psychosocial counseling, patient education, and supporting lifestyle behavior changes including exercise(3)(4). Robust evidence has established that CR participation results in approximately $25 \%$ lower mortality and morbidity(5)(6)(7), with benefits also seen in $\operatorname{LMICs}(8)$, and that $\mathrm{CR}$ is cost-effective(9). Therefore, referral to $\mathrm{CR}$ is highly recommended in cardiac clinical practice guidelines globally(10)(11)(12).

Rates of CR Under-Utilization

Unfortunately, CR is under-utilized around the world(13). CR utilization involves physician referral, subsequent patient enrolment (i.e., attending at least an initial appointment), their adherence to prescribed sessions (on average 2 sessions a week over 5 months)(14), and ultimately program completion, involving a discharge re-assessment(15). Many CR societies recognize these utilization parameters as quality indicators(16), with $7 / 7$ associations with such indicators assessing referral, and 3-4 assessing each of the others(17).

Rates of CR utilization are uniformly low worldwide. Arguably the best (i.e., populationlevel) data we have stems from the United States (US). Based on Get With the Guidelines data, 
referral rates at 156 hospitals were $53 \%$ after acute MI, 58\% after percutaneous coronary intervention (PCI), and 74\% after coronary bypass graft surgery between 2000 and 2007(18). Data from the US' Catheterization/PCI Registry from 1310 hospitals between 2009-2012 show $59.2 \%$ of patients were referred to CR(19). Based on data from the Chest Pain / Myocardial Infarction (MI) registry, CR referral rates increased from 73 to $81 \%$ between 2007 and 2012(20). With regard to enrolment, the US most recently reports 24\% (up from 16-19\% in 1997(21) and 2011(22)) in indicated Medicare beneficiaries $\geq 65$ years (administrative data)(23); After enrollment, $57 \%$ of these patients adhered to $\geq 25 \mathrm{CR}$ sessions, and $27 \%$ completed the full 36 prescribed sessions (i.e., completion)(23).

In Australia, 2012/13 data from the Coronary Angiogram Database of South Australia revealed 53\% of PCI patients were referred to CR(24). In Europe, self-reported CR utilization at up to most recently 131 hospitals in 27 countries revealed $46 \%$ referral, with $69 \%$ of those reporting they attended at least half of prescribed sessions; $32 \%$ of all patients(25). We performed meta-analyses of published literature (not population-based) reporting CR utilization rates, and found overall referral rates at 43\%(26), enrolment at 42\%(27), and adherence at $70 \%$ of prescribed sessions(28).

When compared to implementation of other cardiac guideline recommendations, US registries demonstrate $\mathrm{CR}$ referral is much less well implemented than any other secondary prevention recommendation, be it in inpatients (e.g., $77 \%$ for CR referral vs $98 \%$ for aspirin and smoking cessation counselling for example)(29) or outpatients (e.g., 12\% for CR referral vs 97\% for blood pressure assessment and $81 \%$ for lipid-lowering)(30). We also know there is major geographic variation within jurisdictions, with many areas considered CR “deserts" where patients could not access CR as there is none available (31). 


\section{Reasons for CR Under-Utilization}

These disconcertingly low rates of CR use are caused by factors at the patient, referring physician / acute care, program and health system levels(32)(33). With regard to the former, certain patient groups are less well-represented in programs than others(34)(35). Our CR Barriers Scale (CRBS; https://sgrace.info.yorku.ca/cr-barriers-scale/crbs-instructions-and-languagestranslations/), now available in 14 languages, establishes patient's top barriers as distance from CR sites, transportation barriers, time conflicts, and in many jurisdictions, cost(36). Among nonenrollees, leading barriers include lack of perceived need, which is likely related to another common barrier of lack of awareness, which is itself likely due to lack of clinician encouragement, as well as preference to manage their condition independently(37). Most common reasons for enrollees failing to adhere to prescribed sessions include fatigue or pain due to exercise, preference to exercise at home independently, work conflicts and comorbidities(37).

Hospital-level factors also impact CR utilization, resulting in substantial geographic variation(38). Moreover, it has long been established by Ades et al. that encouragement by physicians in these hospitals is key to patient use of CR, and this finding remains apropos today(39)(40). Yet, unfortunately most discussions between patients and clinicians at the bedside, if they occur at all, do not result in informed patients supported to fully engage in $\mathrm{CR}(41)\left(41^{*}\right)$. Reviews of barriers clinicians experience in referring and encouraging patients to enrol in CR reveal lack of knowledge of CR, its' benefits, as well as locations and how to refer; attitudes towards CR(43); referral norms among colleagues and perceptions it is the role of another clinician to make the referral; safety concerns; time constraints and competing priorities; perception patient lacks motivation or is unable to attend; as well as clinician's personal lifestyle and health beliefs play a role(44)(45). 
At the CR program level, factors such as limited hours, parking costs, language of delivery, and lack of tailoring of programs to meet patient needs (e.g., exercise prescriptions, education, setting, time)(46) play a role in limiting patient engagement(47)(48). At the health system level, lack of reimbursement of CR services (which is particularly disconcerting as other guideline-recommended cardiac care is reimbursed)(49), leading to insufficient capacity(50); lack of integration with acute cardiac care such as through electronic referral for continuity of care(51); and failure to consider location and distribution of programs in relation to where patients reside, all impede CR use(52). With regard to the former, the problem of lack of reimbursement leading to insufficient capacity should not be under-estimated; the International Council of Cardiovascular Prevention and Rehabilitation (ICCPR) has calculated through their recent global audit that countries such as the US, United Kingdom, Canada, Australia and Switzerland have among the best CR densities globally (i.e., spots per incident CVD patient/year)(50), and also determined that such countries have policies for government and/or private healthcare insurance coverage of CR services(53).

\section{Patient-Level Factors}

As outlined above, while overall CR utilization is sub-optimal, certain patients are even less well-represented in CR, particularly women(26)(27)(28). Despite the fact that they are in greater need for CR due to their poorer outcomes(54), and that they may realize even greater benefits than men from full participation(55), women experience different barriers to utilization(56). They are less often referred(26) and encouraged by their clinicians(39), and hence are less aware of the existence of CR and its benefits(37). They more often suffer from comorbidities, such as diabetes, arthritis, and osteoporosis, which they perceive hinder their participation in CR; in actuality, these comorbidities are ameliorated by CR in most cases, or can 
be mitigated with individual program tailoring and thoughtful exercise prescription(57).

Relatedly, women more often report pain or fatigue from exercise(58). They also frequently have transportation barriers, which may be related to their often lower socioeconomic status due to the gender pay gap, and being widowed for example(59). And finally, as women are more often informal caregivers than men, and marry older partners who are hence more prone to chronic illness, women often have family responsibilities they put before their own health care such as participating in $\mathrm{CR}$.

Moreover, older patients, those living outside of urban areas, speaking a first language or being from a culture other than the main one where they live, those with mental health or psychosocial issues, who are unemployed, uncoupled, of lower socioeconomic status as well as those with comorbidities are even less likely to access CR(34). Again, these are patient groups who often have poorer health outcomes than their counterparts, hence would likely benefit from CR to an even greater degree, so these are the patients we should be reaching.

On a final note, patients in LMICs are even less likely to access CR than those in highincome countries (where we have the most data on utilization unfortunately), yet this is where the epidemic of CVD is at its' worst and growing(60). As outlined above, capacity is the leading barrier, with only $1 \mathrm{CR}$ "spot" per 66 incident ischemic heart disease patients per year in LMICs (vs per 3 in high-income countries)(61). While clinician barriers to referral are generally consistent with higher-income countries (e.g., time, awareness of programs)(62)(63)(64), more patients have to pay out-of-pocket in these settings which is clearly a limiting factor(53).

\section{Combatting CR Under-Utilization}


There are established interventions to mitigate under-use that work(65)(66). An excellent review of multi-level CR utilization barriers and corresponding potential mitigation strategies is available in the literature(60). First however, as outlined above, health system capacity must be augmented so there are CR spots to which patients can be referred. How do we achieve this? CR must be covered so the needed resources are there to treat indicated patients in accordance with guideline recommendations(10)(12). A scale to asses healthcare administrator attitudes towards $\mathrm{CR}$ and supporting it is available(67). ICCPR has developed an advocacy toolkit to support reimbursement policy development and enactment (https://globalcardiacrehab.com/Advocacy)(49). They have also developed a high-quality(68) consensus statement, used as the basis of recommendations by the World Health Organization's Package of Rehabilitation Interventions for ischemic heart disease(68), on how CR can feasibly be delivered in low-resource settings, so capacity can be maximized using available resources(3)(4). Moreover, they have developed a corresponding online certification program for would-be CR clinicians from the many disciplines involved in CR(69), to augment CR human resources for delivery (https://globalcardiacrehab.com/Certification).

With regard to the role of programming in maximizing capacity, the nature of $\mathrm{CR}$ services themselves must be optimized to treat as many patients as possible, while maintaining adherence to guidelines, comprehensiveness, safety and patient-centredness. While validation is needed, a useful triage algorithm has been proposed, where patients would be allocated to one of $3 \mathrm{CR}$ models, each requiring a different level of resources and hence cost, on the basis primarily of risk(70) (Figure 2). Programs would develop the following models/ levels of service: (1) comprehensive care supervised by a physician, delivered in clinical centres by a multidisciplinary team for only the highest-risk patients, (2) community-based care exploiting 
technology for self-management for those at moderate risk, and (3) home-based care via technology and leveraging peer support, with the minimum needed care provided by the CR team, for the majority of patients who are at low $\operatorname{risk}(71)(72)$.

\section{Automatic / Systematic CR Referral}

After increasing capacity, the most influential way to augment CR utilization will be to automate referral(73)(74). Given the evidence(5)(6), with corresponding guideline recommendations to refer(10)(12), and given that patients in most countries cannot access CR without a physician referral(75), it is incumbent on those treating indicated patients to refer. A large, seminal multi-centre observational study by our group established that systematic referral results in significantly greater patient enrolment(76). A subsequent review confirmed this effect across different settings(77), and formed the basis for a policy statement on systematic CR referral(78). The evidence continues to mount, particularly given the spread of electronic health records that can be readily leveraged for this purpose(79)(74)(80). Most recently, a randomized, population-based trial of automated CR referral (ISLAND) has established its' efficacy in increasing CR completion $\left(77^{* *}\right)(82)$. In this intervention, all cardiac catheterization patients with obstructive disease randomized to the intervention arms were mailed a pre-filled (using the angiogram information) CR referral form for provision to their primary care provider, along with information on CR benefits and available sites, so the clinician could make the referral(83)(84).

\section{Clinician Encouragement / CR Discussions}

Recently, the Cochrane review on interventions to increase CR enrolment, adherence and completion was updated, and a meta-analysis could be performed for the first time $\left(81^{* *}\right)$.

Twenty-six trials were included, with evidence supporting significant intervention effects in 
increasing all 3 utilization indicators. Meta-regression analyses supported the long-reported observation(40) that clinician encouragement face-to-face significantly improves CR enrolment, bolstering the imperative to empower cardiac care providers to promote $\mathrm{CR}$ to their patients at the bedside (while much work has pointed to "liaisons" from CR programs speaking to patients on acute care wards which is ideal given their CR knowledge, in few institutions are the resources available to support this, and so realistically acute cardiac care providers need to be supported to enact this). Results were translated to clinically-actionable recommendations in a rigorously-developed position statement by the ICCPR which was endorsed by 23 CR-related societies(86), and an online course was developed to support implementation(83*). The evidence-based, free, 20-minute course, which is available in 5 languages (https://globalcardiacrehab.com/CR-Utilization), is approved for continuing education credits by several bodies(88). The course, directed towards all disciplines involved in acute care of CRindicated patients, describes the nature and benefits of $\mathrm{CR}$, how to recognize eligible patients who should be referred, and what key information to impart to patients with encouragement. A point-of-care tool is embedded to support the latter, although it has yet to be validated; more needs to be known about the content and characteristics of patient-clinician discussions and how they can optimally promote patient CR utilization, particularly given the previous research reviewed above demonstrating how infrequently these discussions occur and their insufficiency when they do occur, primarily due to lack of clinician knowledge and time(41)(42)(83*).

\section{What is Being Tried}

Through the Cochrane review, when compared to enrolment, fewer trials for improving the outcomes of adherence and completion were identified, and hence fewer meta-regression analyses to identify what works were possible $\left(81^{* *}\right)$. For completion, no tangible approaches 
were discerned, but the ISLAND trial outlined above has since been published, providing some further direction(77*). For adherence, results suggested offering some CR remotely results in greater adherence. This should be considered preliminary however, because in the included trials adherence was not assessed in a comparative manner in the supervised and remote arms; thus, it is likely adherence was artificially inflated in the remote arms. For example, in our included CR4HER trial, we were hesitant to count answering a call (or logging in to a website in the case of other included trials) as a comparable indicator of attending a session / adherence as taking the time to travel to a CR center, and indeed we did find somewhat lower functional capacity in the home-based arm despite comparable "adherence"(89). Future trials using, for instance, activity monitors over the course of a week as a comparable indicator of adherence regardless of CR setting could resolve this question. Cleary more research is needed in this area to determine what can optimize program adherence, and hence completion. ICCPR has posted the CRBS online for self-report, which could help patients identify their key barriers and share them with programs for mitigation; indeed suggested strategies are provided for each barrier (see: https://globalcardiacrehab.com/For-Patients).

Many CR societies are also actively working to augment CR utilization(90). For instance, to our knowledge, there are currently 8 active CR registries globally(91), of which most assess multiple utilization indicators; what is measured can be reported and improved. This should include focus on measuring use in under-served groups in need, to alleviate inequities. Indeed, the US "Get with the Guidelines" initiative has successfully demonstrated auditing adherence to guideline recommendations including CR referral and supporting institutions in quality improvement results in significantly greater CR utilization(92). 
Moreover, the US has embarked on its' "Million Hearts" initiative(93)(31)(94), which recognizes that one of the top ways to reduce CVD deaths would be through implementation of CR(95). With the American Association of Cardiovascular and Pulmonary Rehabilitation (AACVPR), they have developed a "Change Package" replete with resources for implementing new processes supporting CR utilization (https://millionhearts.hhs.gov/tools-protocols/actionguides/cardiac-change-package/index.html). Finally, they are working with the Agency for Healthcare Research and Quality who funded an initiative called "TAKEheart", where they are implementing automatic referral with care coordination (e.g., bedside CR discussions) at participating hospitals across the country (https://takeheart.ahrq.gov/; Figure 1).

\section{Conclusions}

CR is highly effective in reducing mortality and morbidity, but it is poorly implemented, particularly when compared to other cardiac guideline recommendations. Most patients are not accessing this life-saving intervention, due to factors from the system level (chiefly lack of capacity), through to physician referral failure ascribable commonly to lack of time, and insufficiently-resourced programs that hence cannot innovate to meet patient need(s). Yet, we now know of proven strategies to overcome patient utilization barriers, which could be implemented if we could achieve reimbursement in more countries, and hence augmented capacity. Over the next few years we will all be watching the US -- a country with among the best CR densities in the world, due likely to their successful advocacy for reimbursement(96)(97)-- as they implementing these proven strategies to increase use at a population level. 


\section{Acknowledgments}

Dr. Whooley reports grants from United States Department of Veterans Affairs and the United States National Institutes of Health.

\section{Compliance with Ethical Standards}

Conflict of Interest: All authors declare they have no conflict of interest.

Human and Animal Rights: All reported studies/experiments with human or animal subjects performed by the authors have been previously published and complied with all applicable ethical standards (including the Helsinki declaration and its amendments, institutional/national research committee standards, and international/national/institutional guidelines).

\section{References}

Papers of particular interest, published recently, have been highlighted as:

*Of importance

**Of major importance

1. Kyu HH, Abate D, Abate KH, Abay SM, Abbafati C, Abbasi N, et al. Global, regional, and national disability-adjusted life-years (DALYs) for 359 diseases and injuries and healthy life expectancy (HALE) for 195 countries and territories, 1990-2017: A systematic analysis for the Global Burden of Disease Study 2017. Lancet. 2018;392(10159):1859_ 922. 
2. Jernberg T, Hasvold P, Henriksson M, Hjelm H, Thuresson M, Janzon M. Cardiovascular risk in post-myocardial infarction patients: nationwide real world data demonstrate the importance of a long-term perspective. Eur Heart J. 2015 May 14;36(19):1163-70.

3. Grace SL, Turk-Adawi KI, Contractor A, Atrey A, Campbell N, Derman W, et al. Cardiac rehabilitation delivery model for low-resource settings. Heart. 2016 Sep 1;102(18):1449_ 55.

4. Grace SL, Turk-Adawi KI, Contractor A, Atrey A, Campbell NRC, Derman W, et al. Cardiac Rehabilitation Delivery Model for Low-Resource Settings: An International Council of Cardiovascular Prevention and Rehabilitation Consensus Statement. Vol. 59(3), Progress in Cardiovascular Diseases. 2016. p. 303-22.

5. Anderson L, Oldridge N, Thompson DR, Zwisler A-D, Rees K, Martin N, et al. Exercisebased cardiac rehabilitation for coronary heart disease. J Am Coll Cardiol. 2016;67(1):112.

6. Kabboul N, Tomlinson G, Francis T, Grace S, Chaves G, Rac V, et al. Comparative Effectiveness of the Core Components of Cardiac Rehabilitation on Mortality and Morbidity: A Systematic Review and Network Meta-Analysis. J Clin Med. 2018 Dec 4;7(12):514.

7. van Halewijn G, Deckers J, Tay HY, van Domburg R, Kotseva K, Wood D. Lessons from contemporary trials of cardiovascular prevention and rehabilitation: A systematic review and meta-analysis. Int J Cardiol. 2017;232:294-303.

8. Mamataz T, Uddin J, Alam SI, Taylor R, Grace SL. Effects of cardiac rehabilitation in low and middle-income countries: A systematic review and meta-analysis of randomized 
controlled trials. BMJ. 2021;Under revi.

9. Shields GE, Wells A, Doherty P, Heagerty A, Buck D, Davies LM. Cost-effectiveness of cardiac rehabilitation: a systematic review. Heart. 2018;104(17):1403-10.

10. Smith SC, Benjamin EJ, Bonow RO, Braun LT, Creager M a, Franklin BA, et al. AHA/ACCF secondary prevention and risk reduction therapy for patients with coronary and other atherosclerotic vascular disease: 2011 update. Circulation. 2011 Nov 29;124(22):2458-73.

11. Guha S, Sethi R, Ray S, Bahl VK, Shanmugasundaram S, Kerkar P, et al. Cardiological Society of India: Position statement for the management of ST elevation myocardial infarction in India. Indian Heart J. 2017 Oct 9;69(11):S63-97.

12. Piepoli MF, Hoes AW, Agewall S, Albus C, Brotons C, Catapano AL, et al. 2016 European Guidelines on cardiovascular disease prevention in clinical practice. Eur Heart J. 2016 Aug 1;37(29):2315-81.

13. Turk-Adawi KI, Grace SL. Narrative review comparing the benefits of and participation in cardiac rehabilitation in high-, middle- and low-income countries. Heart Lung Circ. 2015 May;24(5):510-20.

14. Chaves G, Turk-Adawi K, Supervia M, Santiago de Araújo Pio C, Abu-Jeish A-H, Mamataz T, et al. Cardiac Rehabilitation Dose Around the World: Variation and Correlates. Circ Cardiovasc Qual Outcomes. 2020 Jan;13(1):e005453.

15. Santiago de Araújo Pio C, Beckie TM, Varnfield M, Sarrafzadegan N, Babu AS, Baidya S, et al. Promoting patient utilization of outpatient cardiac rehabilitation: A joint 
International Council and Canadian Association of Cardiovascular Prevention and Rehabilitation position statement. Int J Cardiol. 2020 Jan 1;298:1-7.

16. Grace, S.L., Poirier, P., Norris, C.M., Oakes, G., Somanader, D. , \& Suskin N. PanCanadian development of cardiac rehabilitation and secondary prevention quality indicators. Can J Cardiol. 2014;30(8):945-8.

17. Moghei M, Oh P, Chessex C, Grace SL. Cardiac Rehabilitation Quality Improvement: A Narrative Review. J Cardiopulm Rehabil Prev. 2019;39(4):226-34.

18. Brown TM, Hernandez AF, Bittner V, Cannon CP, Ellrodt G, Liang L, et al. Predictors of Cardiac Rehabilitation Referral in Coronary Artery Disease Patients. Findings From the American Heart Association's Get With The Guidelines Program. J Am Coll Cardiol. 2009 Aug 4;54(6):515-21.

19. Aragam KG, Dai D, Neely ML, Bhatt DL, Roe MT, Rumsfeld JS, et al. Gaps in referral to cardiac rehabilitation of patients undergoing percutaneous coronary intervention in the United States. J Am Coll Cardiol. 2015 May 19;65(19):2079-88.

20. Beatty AL, Li S, Thomas L, Amsterdam EA, Alexander KP, Whooley MA. Trends in referral to cardiac rehabilitation after myocardial infarction: Data from the national cardiovascular data registry 2007 to 2012. Vol. 63, Journal of the American College of Cardiology. Elsevier USA; 2014. p. 2582-3.

21. Suaya JA, Shepard DS, Normand S-LT, Ades P a, Prottas J, Stason WB. Use of cardiac rehabilitation by Medicare beneficiaries after myocardial infarction or coronary bypass surgery. Circulation. 2007 Oct 9;116(15):1653-62. 
22. Beatty AL, Truong M, Schopfer DW, Shen H, Bachmann JM, Whooley MA. Geographic variation in cardiac rehabilitation participation in medicare and veterans affairs populations: an opportunity for improvement? Circulation. 2018 Jan 5;137:1899-908.

23. Ritchey MD, Maresh S, McNeely J, Shaffer T, Jackson SL, Keteyian SJ, et al. Tracking Cardiac Rehabilitation Participation and Completion Among Medicare Beneficiaries to Inform the Efforts of a National Initiative. Circ Cardiovasc Qual Outcomes. 2020;13:e005902.

24. Tavella R, Kennedy K, Beltrame JF, Spertus J, Rumsfeld J. Characteristics and Outcomes of Patients Undergoing Cardiac Catheterisation Procedures in US versus Australian Hospitals. Circ Cardiovasc Qual Outcomes. 2014;7:A383.

25. Kotseva K, De Backer G, De Bacquer D, Rydén L, Hoes A, Grobbee D, et al. Lifestyle and impact on cardiovascular risk factor control in coronary patients across 27 countries: Results from the European Society of Cardiology ESC-EORP EUROASPIRE V registry. Eur J Prev Cardiol. 2019 May 1;26(8):824-35.

26. Colella TJ, Gravely S, Marzolini S, Grace SL, Francis JA, Oh P, et al. Sex bias in referral of women to outpatient cardiac rehabilitation? A meta-analysis. Eur J Prev Cardiol. 2015 Apr 28;22(4):423-41.

27. Samayoa L, Grace SL, Gravely S, Scott LB, Marzolini S, Colella TJF, et al. Sex differences in cardiac rehabilitation enrollment: a meta-analysis. Can J Cardiol. 2014 Jul;30(7):793-800.

28. Oosenbrug E, Marinho RP, Zhang J, Marzolini S, Colella TJF, Pakosh M, et al. Sex differences in cardiac rehabilitation adherence: a meta-analysis. Can J Cardiol. 2016 
Nov;32(11):1316-24.

29. Harrison RW, Simon D, Miller AL, De Lemos JA, Peterson ED, Wang TY. Association of hospital myocardial infarction volume with adherence to American College of Cardiology/American Heart Association performance measures: Insights from the National Cardiovascular Data Registry. Am Heart J. 2016;178:95-101.

30. Virani SS, Maddox TM, Chan PS, Tang F, Akeroyd JM, Risch SA, et al. Provider type and quality of outpatient cardiovascular disease care insights from the NCDR PINNACLE registry. J Am Coll Cardiol. 2015 Oct 20;66(16):1803-12.

31. Wall HK, Stolp H, Wright JS, Ritchey MD, Thomas RJ, Ades PA, et al. The Million Hearts Initiative: Catalyzing Utilization of CR and Accelerating Implementation of New Care Models. J Cardiopulm Rehabil Prev. 2020 Sep 1;40(5):290-3.

32. Clark AM, King-Shier KM, Duncan A, Spaling M, Stone JA, Jaglal S, et al. Factors influencing referral to cardiac rehabilitation and secondary prevention programs: A systematic review. Vol. 20, European Journal of Preventive Cardiology. Eur J Prev Cardiol; 2013. p. 692-700.

33. Sérvio TC, Britto RR, De Melo Ghisi GL, Da Silva LP, Silva LDN, Lima MMO, et al. Barriers to cardiac rehabilitation delivery in a low-resource setting from the perspective of healthcare administrators, rehabilitation providers, and cardiac patients. BMC Health Serv Res. 2019 Sep 2;19(1):615.

34. Ruano-Ravina A, Pena-Gil C, Abu-Assi E, Raposeiras S, van 't Hof A, Meindersma E, et al. Participation and adherence to cardiac rehabilitation programs. A systematic review. Int J Cardiol. 2016;223:436-43. 
35. Rose M, Timmons SM, Amerson R, Reimels E, Pruitt RH. Facilitators and barriers in cardiac rehabilitation participation: An integrative review. J Nurse Pract. 2011 May $1 ; 7(5): 399-408$.

36. Shanmugasegaram S, Gagliese L, Oh P, Stewart DE, Brister SJ, Chan V, et al. Psychometric validation of the Cardiac Rehabilitation Barriers Scale. Clin Rehabil. $2012 ; 26(2)$.

37. Grace SL, Gravely-Witte S, Kayaniyil S, Brual J, Suskin N, Stewart DE. A multisite examination of sex differences in cardiac rehabilitation barriers by participation status. $\mathbf{J}$ women's Heal. 2009 Feb;18(2):209-16.

38. Thompson MP, Yaser JM, Hou H, Syrjamaki JD, DeLucia A, Likosky DS, et al. Determinants of Hospital Variation in Cardiac Rehabilitation Enrollment During Coronary Artery Disease Episodes of Care. Circ Cardiovasc Qual Outcomes. 2021 Feb 5;14(2):e007144.

39. Tsui CK-Y, Shanmugasegaram S, Jamnik V, Wu G, Grace SL. Variation in Patient Perceptions of Healthcare Provider Endorsement of Cardiac Rehabilitation. J Cardiopulm Rehabil Prev. 2012;32(4):192-7.

40. Ades PA, Waldmann ML, Polk DM, Coflesky JT. Referral patterns and exercise response in the rehabilitation of female coronary patients aged $\geq 62$ years. Am J Cardiol. 1992 Jun $1 ; 69(17): 1422-5$.

41. Pourhabib S, Kentner AC, Grace SL. The impact of patient-healthcare provider discussions on enrollment in cardiovascular rehabilitation. J Rehabil Med. 2014 Oct;46(9):924-31. 
42. *Mitoff PR, Wesolowski M, Abramson BL, Grace SL. Patient-Provider Communication Regarding Referral to Cardiac Rehabilitation. Rehabil Nurs. 2020 Sep 1;45(5):245-51. This study, originally published in 2005 but reprinted in 2020 due to its importance, is among the few studies probing patients regarding their perceptions of their CR discussions with their providers, discussions that are established as a key determinant in their ultimate CR utilization.

43. Ghisi GL de M, Grace SL. Validation of the Physician Attitudes toward Cardiac Rehabilitation and Referral (PACRR) Scale. Hear Lung Circ. 2019 Aug 1;28(8):1218-24.

44. Ghisi GLM, Polyzotis P, Oh P, Pakosh M, Grace SL. Physician factors affecting cardiac rehabilitation referral and patient enrollment: A systematic review. Vol. 36, Clinical Cardiology. 2013. p. 323-35.

45. Gallagher R, Neubeck L, Du H, Astley C, Berry NM, Hill MN, et al. Facilitating or getting in the way? the effect of clinicians' knowledge, values and beliefs on referral and participation. Vol. 23, European Journal of Preventive Cardiology. SAGE Publications Inc.; 2016. p. 1141-50.

46. Vidal-Almela S, Czajkowski B, Prince SA, Chirico D, Way KL, Pipe AL, et al. Lessons learned from community- and home-based physical activity programs: A narrative review of factors influencing women's participation in cardiac rehabilitation. Eur J Prev Cardiol. 2020;

47. Pack QR, Squires RW, Lopez-Jimenez F, Lichtman SW, Rodriguez-Escudero JP, Zysek VN, et al. The Current and Potential Capacity for Cardiac Rehabilitation Utilization in the United States. J Cardiopulm Rehabil Prev. 2014;34:318-26.

48. Pack QR, Squires RW, Lopez-Jimenez F, Lichtman SW, Rodriguez-Escudero JP, 
Lindenauer PK, et al. Participation Rates, Process Monitoring, and Quality Improvement among Cardiac Rehabilitation Programs in the United States: A NATIONAL SURVEY. J Cardiopulm Rehabil Prev. 2015 Dec 1;35(3):173-80.

49. Babu AS, Lopez-Jimenez F, Thomas RJ, Isaranuwatchai W, Herdy AH, Hoch JS, et al. Advocacy for outpatient cardiac rehabilitation globally. BMC Health Serv Res. 2016 Dec 6;16(1):471.

50. Turk-Adawi K, Supervia M, Lopez-Jimenez F, Pesah E, Ding R, Britto RR, et al. Cardiac rehabilitation availability and density around the globe. EClinicalMedicine. 2019 Aug;13:31-45.

51. Gurewich D, Prottas J, Bhalotra S, Suaya JA, Shepard DS. System-level factors and use of cardiac rehabilitation. J Cardiopulm Rehabil Prev. 2008;28(6):380-5.

52. Leung YW, Brual J, Macpherson A, Grace SL, Leung, YW, Brual, J., Macpherson, A., Grace SL. Geographic issues in cardiac rehabilitation utilization: A narrative review. Health Place. 2010 Nov;16(6):1196-205.

53. Moghei M, Pesah E, Turk-Adawi K, Supervia M, Jimenez FL, Schraa E, et al. Funding sources and costs to deliver cardiac rehabilitation around the globe: Drivers and Barriers. Int J Cardiol. 2019 Feb 1;276:278-86.

54. Norris CM, Yip CYY, Nerenberg KA, Clavel MA, Pacheco C, Foulds HJA, et al. State of the Science in Women's Cardiovascular Disease: A Canadian Perspective on the Influence of Sex and Gender. J Am Heart Assoc. 2020;9(4):e015634.

55. Colbert JD, Martin BJ, Haykowsky MJ, Hauer TL, Austford LD, Arena RA, et al. Cardiac 
rehabilitation referral, attendance and mortality in women. Eur J Prev Cardiol. 2015;22(8):979-86.

56. Supervía M, Medina-Inojosa JR, Yeung C, Lopez-Jimenez F, Squires RW, Pérez-Terzic CM, et al. Cardiac Rehabilitation for Women: A Systematic Review of Barriers and Solutions. Mayo Clin Proc. 2017;92(4):565-77.

57. Pedersen BK, Saltin B. Exercise as medicine - evidence for prescribing exercise as therapy in 26 different chronic diseases. Scand J Med Sci Sports. 2015 Dec 1;25:1-72.

58. Moore SM, Kramer FM. Women's and men's preferences for cardiac rehabilitation program features. J Cardiopulm Rehabil. 1996;16(3):163-8.

59. Connelly PJ, Azizi Z, Alipour P, Delles C, Pilote L, Raparelli V. The importance of Gender to Understand Sex Differences in Cardiovascular Disease. Can J Cardiol. 2021 Feb;0(0):epub.

60. Ragupathi L, Stribling J, Yakunina Y, Fuster V, Mclaughlin MA, Vedanthan R. Availability, use, and barriers to cardiac rehabilitation in LMIC. Glob Heart. 2016;12(4):323-34.

61. Pesah E, Turk-Adawi K, Supervia M, Lopez-Jimenez F, Britto R, Ding R, et al. Cardiac rehabilitation delivery in low/middle-income countries. Heart. 2019 Jun 28;105(23):180612.

62. Ghisi GL de M, Contractor A, Abhyankar M, Syed A, Grace SL. Cardiac rehabilitation knowledge, awareness, and practice among cardiologists in India. Indian Heart J. 2018;70(5):753-5. 
63. Liu X, Grace SL, Ding B, Liang L, Xu Z, Zhang Y. Cardiac rehabilitation perceptions among healthcare providers in China: A mixed-method study. Altern Ther Health Med. 2021; Under revision.

64. Ghanbari-Firoozabadi M, Mirzaei M, Nasiriani K, Hemati M, Entezari J, Vafaeinasab M, et al. Cardiac Specialists' Perspectives on Barriers to Cardiac Rehabilitation Referral and Participation in a Low-Resource Setting. Rehabil Process Outcome. 2020 Jan 25;9:epub.

65. Gravely-Witte S, Leung YW, Nariani R, Tamim H, Oh P, Chan VM, et al. Effects of cardiac rehabilitation referral strategies on referral and enrollment rates. Nat Rev Cardiol. 2010;7(2).

66. Santiago de Araújo Pio C, Chaves GS, Davies P, Taylor RS, Grace SL. Interventions to promote patient utilisation of cardiac rehabilitation. Cochrane Database Syst Rev. 2019;2:CD007131.

67. Chaves GSS, Ghisi GLM, Britto RR, Servio C, Cribbie R, Pack Q, et al. Health Care Administrators' Attitudes Toward Cardiac Rehabilitation(HACRA) in North and South America and the Development of a Scale to Assess Them. Hear Lung Circ. 2020;29(7):e111-e120.

68. Mehra VM, Gaalema DE, Pakosh M, Grace SL. Systematic review of cardiac rehabilitation guidelines: Quality and scope. Eur J Prev Cardiol. 2020 Jun 4;27(9):912-28.

69. Babu AS, Heald FH, Contractor A, Ghisi GLM, Buckley J, Mola A, et al. Building capacity in cardiac rehabilitation through the International Council of Cardiovascular Prevention and Rehabilitation's Cardiac Rehabilitation Foundations Certification (CRFC) program: Evaluation of reach, barriers and impact. Cardiol Res Pract. 2021;Under review. 
70. Sandesara PB, Dhindsa D, Khambhati J, Lee SK, Varghese T, O'Neal WT, et al. Reconfiguring Cardiac Rehabilitation to Achieve Panvascular Prevention: New Care Models for a New World. Can J Cardiol. 2018;34:S231-9.

71. Grace SL, Turk-Adawi K, Pio CS de A, Alter DA. Ensuring cardiac rehabilitation access for the majority of those in need: A call to action for Canada. Can J Cardiol. 2016 Jul;32(10):S358-64.

72. Sandesara PB, Lambert CT, Gordon NF, Fletcher GF, Franklin BA, Wenger NK, et al. Cardiac Rehabilitation and Risk Reduction: Time to "rebrand and Reinvigorate." J Am Coll Cardiol. 2015;65(4):389-95.

73. Adusumalli S, Jolly E, Chokshi NP, Gitelman Y, Rareshide CAL, Kolansky DM, et al. Referral Rates for Cardiac Rehabilitation Among Eligible Inpatients After Implementation of a Default Opt-Out Decision Pathway in the Electronic Medical Record. JAMA Netw open. 2021 Jan 4;4(1):e2033472.

74. Liu H, Wilton SB, Southern DA, Knudtson ML, Maitland A, Hauer T, et al. Automated Referral to Cardiac Rehabilitation After Coronary Artery Bypass Grafting Is Associated With Modest Improvement in Program Completion. Can J Cardiol. 2019 Nov $1 ; 35(11): 1491-8$.

75. Supervia M, Turk-Adawi K, Lopez-Jimenez F, Pesah E, Ding R, Britto RR, et al. Nature of Cardiac Rehabilitation Around the Globe. EClinicalMedicine. 2019 Aug 1;13:46-56.

76. Grace SL, Russell KL, Reid RD, Oh P, Anand S, Rush J, et al. Effect of cardiac rehabilitation referral strategies on utilization rates: a prospective, controlled study. Arch Intern Med. 2011 Feb 14;171(3):235-41. 
77. Gravely-Witte S, Leung YW, Nariani R, Tamim H, Oh P, Chan VM, et al. Effects of cardiac rehabilitation referral strategies on referral and enrollment rates. Nat Rev Cardiol. 2010 Feb;7(2):87-96.

78. Grace SL, Chessex C, Arthur H, Chan S, Cyr C, Dafoe W, et al. Systematizing inpatient referral to cardiac rehabilitation 2010: Canadian association of cardiac rehabilitation and canadian cardiovascular society joint position paper. Can J Cardiol. 2011 Mar $1 ; 27(2): 192-9$.

79. Miralles KV, S.L. G, Cuenza L. Trends in cardiac rehabilitation enrollment post-coronary bypass grafting upon implementation of an institutional clinical pathway-based automatic referral system in a low-resource setting. J HongKong Coll Cardiol. 2020;28(2):87.

80. Pirruccello JP, Traynor KC, Natarajan P, Brown C, Hidrue MK, Rosenfield KA, et al. An electronic cardiac rehabilitation referral system increases cardiac rehabilitation referrals. Coron Artery Dis. 2017;28(4):342-5.

81. **Ivers NM, Schwalm JD, Bouck Z, McCready T, Taljaard M, Grace SL, et al. Interventions supporting long term adherence and decreasing cardiovascular events after myocardial infarction (ISLAND): Pragmatic randomised controlled trial. BMJ. 2020 Jun 10;369. This is the only randomized trial of systematic CR referral.

82. McCleary N, Ivers NM, Schwalm JD, Witteman HO, Taljaard M, Desveaux L, et al. Interventions Supporting Cardiac Rehabilitation Completion: Process Evaluation Investigating Theory- Based Mechanisms of Action. Heal Psychol. 2020;

83. Witteman HO, Presseau J, Nicholas Angl E, Jokhio I, Schwalm J, Grimshaw JM, et al. Negotiating Tensions Between Theory and Design in the Development of Mailings for 
People Recovering From Acute Coronary Syndrome. JMIR Hum Factors. 2017 Mar 1;4(1):e6.

84. Ivers N, Schwalm JD, Witteman HO, Presseau J, Taljaard M, McCready T, et al. Interventions Supporting Long-term Adherence aNd Decreasing cardiovascular events (ISLAND): Pragmatic randomized trial protocol. Am Heart J. 2017 Aug 1;190:64-75. 85. **Santiago de Araújo Pio C, Chaves GS, Davies P, Taylor RS, Grace SL. Interventions to promote patient utilisation of cardiac rehabilitation. Cochrane Database Syst Rev. 2019 Feb 1;2(2):CD007131. In this update of the 2014 review, a quantitative analysis of utilization interventions is performed for the first time, revealing tangible strategies to increase patient enrolment in particular.

86. Santiago De Araújo Pio C, Beckie TM, Varnfield M, Sarrafzadegan N, Babu AS, Baidya S, et al. Promoting Patient Utilization of Outpatient Cardiac Rehabilitation: A Joint International Council and Canadian Association of Cardiovascular Prevention and Rehabilitation Position Statement. J Cardiopulm Rehabil Prev. 2020 Mar;40(2):79-86.

87. *Santiago de Araújo Pio C, Gagliardi A, Suskin N, Ahmad F, Grace SL. Implementing recommendations for inpatient healthcare provider encouragement of cardiac rehabilitation participation: development and evaluation of an online course. BMC Health Serv Res. 2020 Aug 20;20(1):768. This is the only available course to our knowledge to inform providers about the importance of their CR endorsement to patients and how to do it.

88. Heald F, Santiago Pio C, Liu X, Rivera Thereul F, Pavy B, Grace SL. Evaluation of an online course in five languages for inpatient cardiac care providers on promoting cardiac 
rehabilitation: Reach, effects and satisfaction. J Cardiopulm Rehabil Prev. 2021;Under review.

89. Grace SL, Midence L, Oh P, Brister S, Chessex C, Stewart DE, et al. Cardiac rehabilitation program adherence and functional capacity among women: a randomized controlled trial. Mayo Clin Proc. 2016 Feb;91(2):140-8.

90. Thomas E, Grace SL, Boyle D, Gallagher R, Neubeck L, Cox N, et al. Utilising a Data Capture Tool to Populate a Cardiac Rehabilitation Registry: A Feasibility Study. Hear Lung Circ. 2020 Feb 1;29(2):224-32.

91. Poffley A, Thomas E, Grace SL, Neubeck L, Gallagher R, Niebauer J, et al. A systematic review of cardiac rehabilitation registries. Eur J Prev Cardiol. 2017;24(15):1596-609.

92. LaBresh K a, Fonarow GC, Smith SC, Bonow RO, Smaha LC, Tyler P a, et al. Improved treatment of hospitalized coronary artery disease patients with the get with the guidelines program. Crit Pathw Cardiol. 2007 Sep;6(3):98-105.

93. Ades PA, Keteyian SJ, Wright JS, Hamm LF, Lui K, Newlin K, et al. Increasing Cardiac Rehabilitation Participation From 20\% to 70\%: A Road Map From the Million Hearts Cardiac Rehabilitation Collaborative. Vol. 92, Mayo Clinic Proceedings. Elsevier Ltd; 2017. p. 234-42.

94. Frieden TR, Berwick DM. The "Million Hearts" Initiative — Preventing Heart Attacks and Strokes. N Engl J Med. 2011;365(13).

95. Kottke TE, Faith D a, Jordan CO, Pronk NP, Thomas RJ, Capewell S. The comparative effectiveness of heart disease prevention and treatment strategies. Am J Prev Med. 2009 
Jan;36(1):82-8.

96. Thomas RJ, Chiu JS, Goff DC, King M, Lahr B, Lichtman SW, et al. Reliability of abstracting performance measures: Results of the cardiac rehabilitation referral and reliability (CR3) project. J Cardiopulm Rehabil Prev. 2014;34(3):172-9.

97. Thirapatarapong W, Thomas RJ, Pack Q, Sharma S, Squires RW. Commercial insurance coverage for outpatient cardiac rehabilitation in patients with heart failure in the United States. J Cardiopulm Rehabil Prev. 2014 Dec 10;34(6):386-9. 


\section{Figure 1}

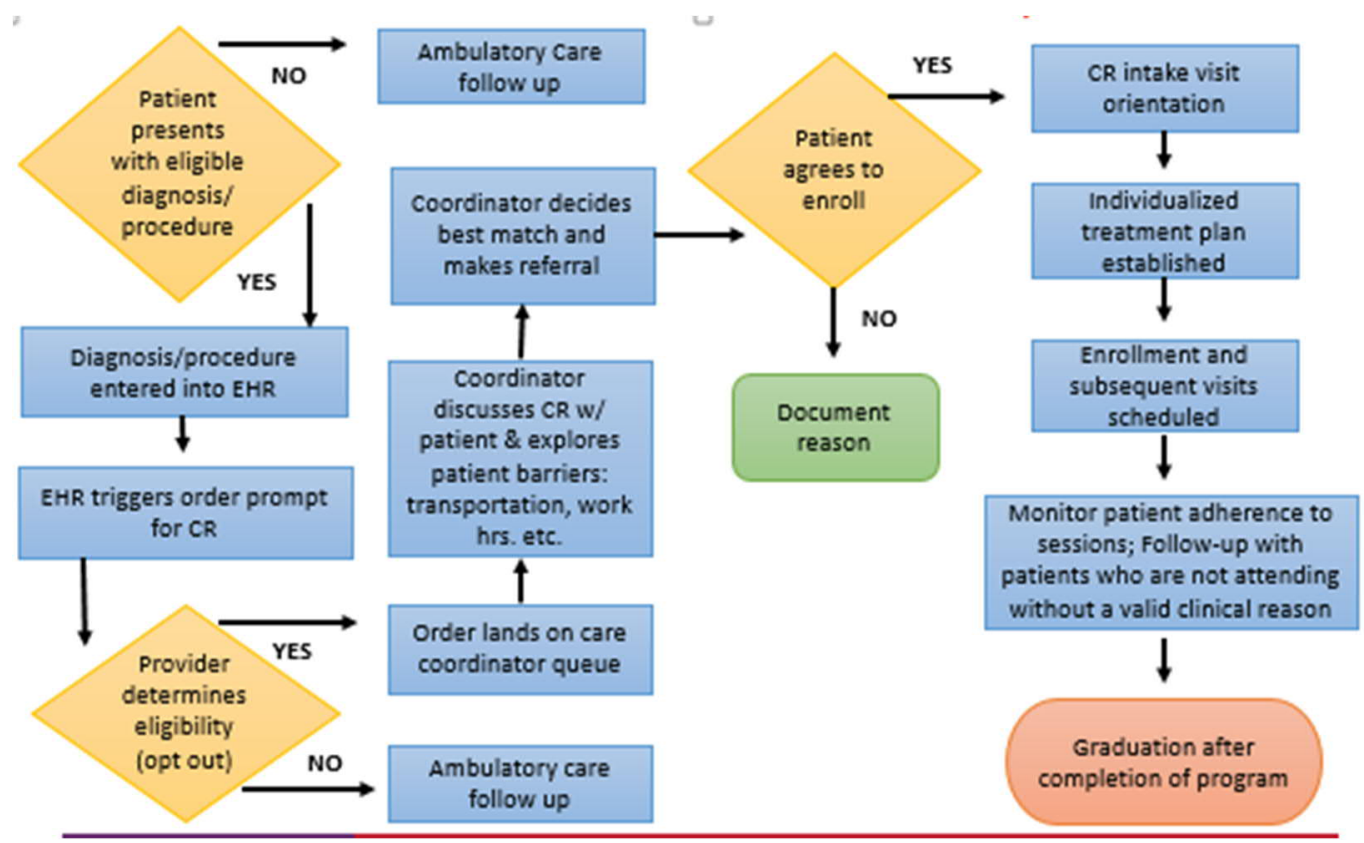

Figure 1: Process for Automatic Cardiac Rehabilitation Referral, with Care Coordination to Support Patient Enrolment, Adherence, and Completion. CR: cardiac rehabilitation; EHR: electronic health record. (With permission from: The Agency for Healthcare Research and Quality. TAKEheart: AHRQ's Initiative to Increase Use of Cardiac Rehabilitation.

https://takeheart.ahrq.gov/.) 
Figure 2

\section{High-Risk}

- Comprehensive CR as delivered on-site

- Multidisciplinary Team

- Physician supervised/nurse-case managed

\section{Intermediate- Risk}

- Community- based model

- Home-based/"Hybrid" model

- E-health, M-health, Telehealth

\section{Low-Risk}

- Peer and self-monitored only

- Limited supervised sessions

- E-Health, M-health, Telehealth

Triaging Patients to Less Resource-Intensive Models as a Means to Increase CR Capacity

Proposed framework for CR models at three levels of resource intensity to which patients could be allocated based on their clinical risk. Cost efficiency of models of lesser intensity requires confirmation.

$\mathrm{CR}=$ Cardiac Rehabilitation

(Reprinted from: Sandesara PB, et al. Can J Cardiol. 2018;34:S231-9, with permission from Elsevier) [70]. 